WORK IN PROGRESS

\title{
Self-monitoring of blood glucose: The user experience and device interactions of older adults with type 2 diabetes mellitus
}

\author{
S. Daphne Prado-Jimenez, Rosa Amelia Rosales- \\ Cinco, Carlos Aceves-Gonzalez, Alexandra R. Lang
}

Published: 31 October 2018

\begin{abstract}
In Mexico, the Type 2 Diabetes mellitus (DM2) is a public health problem and causes early mortality. The highest prevalence is in the elderly population, between 60 and 79 years. Adherence to the treatment and the self-monitoring of blood glucose is often poor. For patients with DM2, the self-monitoring of blood glucose is a useful tool in the management of this chronic condition because it helps to establish a profile of blood glucose levels and to know how the patient is responding to nutrition and pharmacotherapy. This project is being developed with the aim to identify the requirements of older adults with diabetes mellitus type 2 for the use of the glucometer. It will be carried out clinician interviews and individual trials with older adults who suffer this illness. This paper also aims to share a learning experience with the HumanComputer Interaction community working within the medical device industry.
\end{abstract}

Keywords: Ergonomics; Medical device; User requirements.

\section{Introduction}

Type 2 diabetes mellitus (DM2) is a chronic metabolic condition with hyperglycemia status in blood levels above normal physiological limits [13], and it affects $9.4 \%$ of the population aged 20 years old and over in Mexico [3]. The highest prevalence DM2 is between people aged 60 and 79 years, $55.2 \%[3,18]$. The complications of diabetes reported in Mexico by the National Health and Nutrition Survey (ENSANUT) in 2016 are: $54.5 \%$ decreased vision, $11.2 \%$ retinal damage, $9.95 \%$ loss of sight, 9.1 $\%$ ulcers, $5.5 \%$ amputation of some member, $3.2 \%$ heart attack, $1.7 \%$ diabetic coma, and $1.2 \%$ dialysis [3]; and the DM2 is one

\footnotetext{
Prado-Jimenez, SD., Rosales-Cinco, RA., Aceves-Gonzalez, C. Ergonomics Research Center, Master in Ergonomics, University Center of Art, Architecture and Design, University of Guadalajara Guadalajara, Mexico.

Email: prado.jsd@gmail.com, rosa.rcinco@academicos.udg.mx, c.aceves@academicos.udg.mx

Lang, AR.

NIHR MindTech Healthcare Technology Co-operative, Institute of

Mental Health, University of Nottingham, Jubilee Campus.

Nottingham, United Kingdom.

Email: alexandra.lang@ nottingham.ac.uk
}

of the 10 most frequent causes of hospitalization in adults $[3,18]$. Nevertheless when the patient with DM2 receives proper treatment and he/she is under proper glucose monitoring the complications can decrease $[14,16]$. One thing that can assist in good monitoring practices is safe to use, well designed medical devices where the user interactions are understood and designed into the device interfaces $[10,12]$.

\subsection{Self-monitoring of Blood Glucose and Non- Adherence}

The chronic condition diabetes is a dynamic and complex system, where the patient is required to adhere to the treatment, becomes an expert in self-monitoring of blood glucose (SMBG) and understanding the disease, turns out the disease in a daily and complex task [11]. To be an expert in SMBG, the patient needs to use properly the medical device blood glucose meter (BGM); a previous hierarchical task analysis (HTA) to BGM showed that there are three general steps to measuring glucose level, but these three steps require 52 sub-steps to reach the main goal [17]. It might be more difficult for the elderly population, not only "because they may have to remember sequences of steps to operate them properly" [15], but also because of unfamiliarity with computerized devices, changes in vision, hearing, memory, problem-solving ability and manual dexterity [4].

The SMBG is one of the most useful tools in the control of diabetes $[9,16]$ if the BGM is used correctly. Proper SMBG provides information about an individual's dynamic blood glucose profile, and with this profile, the clinician can administer a good dose of insulin or medication to the patient [9]. According to the Mexican Diabetes Federation (2017) four out of ten patients, in Mexico, do not monitor their glucose as often as recommended by their clinicians, and $60 \%$ of patients do not reach the goal of glycemic control [14].

\subsection{Involving Users}

The healthcare sector requires a clinically effective, safe and well designed medical device $[10,12]$. The developers need to ensure the medical device has these characteristics. Therefore they must consider the user's requirements, such as user capabilities, user's desire, user work patterns, lifestyles, environments in which the device will be used and the system of which it will be a part [12]. Wherever possible, these aspects must be taken into account to 
prevent the device from failing when the user uses it in a real context [6]. Human Factors/Ergonomics with a user-centred and a system approach has the potential to play an important role improving the interaction between the user and BGM of medical devices and from this perspective usable medical device have been generated [7].

The international standard, ISO 62366 mentions the incorporation of usability engineering to medical devices to help ensure devices are usable and free from errors; this mention formalises the need for developers to consider usability in their devices. The Food and Drug Administration (FDA) of the United States of America requires developers to incorporate the principles of Human Factors throughout the development process.

\subsection{The Goal of the Study}

This paper presents a work in progress which is part of a master's project in Ergonomics, and it is focused on the interaction between elderly with diagnosed with DM2 and the blood glucose meter (BGM). The study will be using Ergonomics as a scientific discipline and qualitative methods to identify the elderly users' requirements for BGM. It will be sought to obtain the users' requirements from the clinicians and the patients with DM2. These requirements capture not only usability information, but also information about who is the real user. Also, it is expected to identify the social support that older adults have when they are learning and doing the SMBG, the compatibility of these people capabilities and the demands of the SMBG, along with their needs and desires. The study will allow considerate what are the training needs of older people with DM2 to understand the BGM wider interactions of its use in a real context.

\section{Method}

This paper details the study design. The project has two stages of data collection; the first stage is composed of semi-structured interviews with clinicians and the second comprises individual trials with older people with DM2.

\subsection{Clinicians Interviews}

Phase 1 will explore and describe the perception of the people working within the public healthcare organisation providing medical care to patients with DM2 in México, the Mexican Social Security Institute (IMSS) [3, 5]. The methodology in this phase includes undertaking a series of semi-structured interviews with clinicians (see Figure 1). The aim of the interviews is three-fold: (1) identify the organisational aspects that influence or affect the use of the glucometer in older patients with DM2. (2) Recognise the usability issues detected by the clinicians in these patients with the use of the BGM and whether these characteristics differ with the rest of the population (children, adolescents and adults with DM2). (3) Getting a better understanding of the importance of using the BGM within the treatment of DM2 in an older patient.

\subsubsection{Pilot interviews}

To assess and develop the semi-structured interview a pilot was conducted. This pilot included interviewing six clinicians with a speciality in family medicine (FM), with an average of the years of experience (6.1 years, SD +-2.56$)$, with a range of 3 to 9 years. None of the doctors in FM said to give consultation in the private sector. The interview was carried out individually in the office of each FM doctor after their working day, thus to avoid distractions or interruptions in their daily consultations.

The preliminary results of the pilot showed that the most common errors in older adults are: bigger or smaller blood drop, use the same finger in the test, unclean hands, not review the expiration of the test strip, not following the sequence of the task. Another factor was buying the BGM in the United States of America and not knowing how to interpret the results. The factors that the clinicians consider as an influence for the patient not using the BGM are the cost of use, pain, not awareness of the use, a big sensibility to pain, dementia, cognitive problems, and depression.
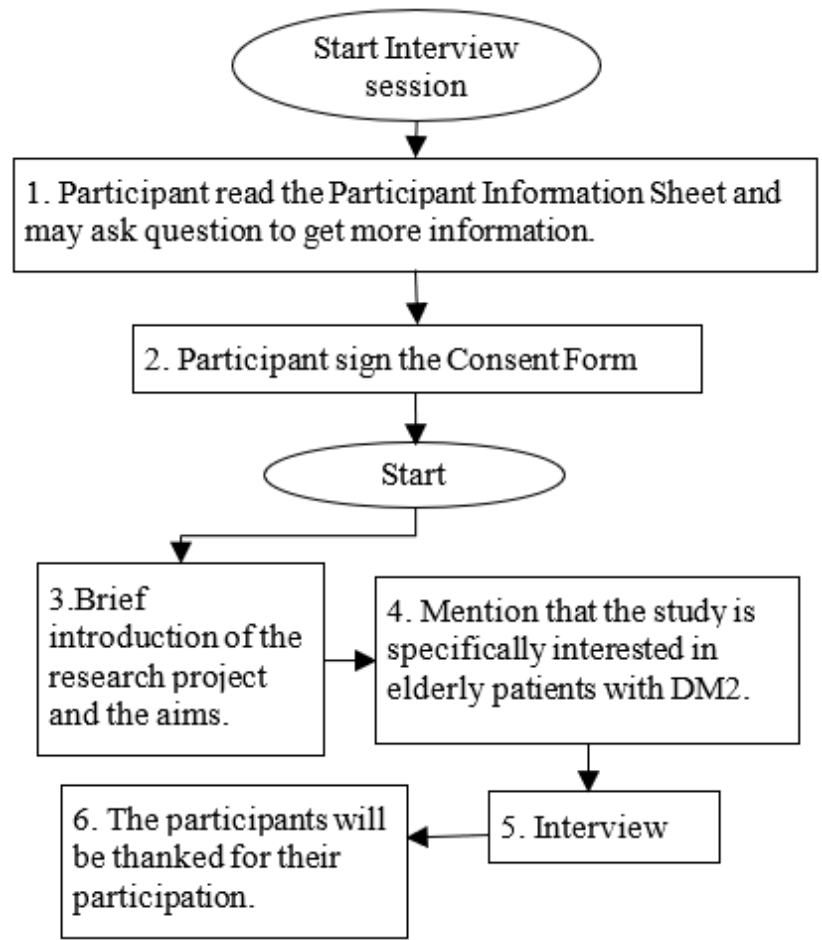

Figure 1. Clinician's Interview Process.

After conducting the pilot, the team of researchers decided to group the interview into 6 aspects: (1) Clinicians' Background; (2) Blood glucose meter in the home and use; (3) Errors, (4) Factors that can influence the use; (5) Context and support by the IMSS, and (6) Information that patients receive. After the pilot interview, it was added the section of clinician's background because it was decided to perform the interview including general practitioners in the United Kingdom, this would allow improving the understanding of how BGM is used in two different cultural settings and therefore improve understanding about cultural needs regarding medical HCI applications.

\subsubsection{Participants}

In this interview, a non-probabilistic intentional sample will be used, in which the participants can be health professionals, with at least one year of experience in the IMSS, and who treat older patients diagnosed with DM2. The interviews will be done to clinicians with a specialist in family medicine (FM) because they are the first level of medical care in the IMSS, and they have frequent contact with patients diagnosed with the illness.

\subsubsection{Semi-structured Interview Process}

In the beginning, the participant will be asked to read carefully and proceed to sign the Consent Form. The interviews will begin with a brief introduction of the research Project and then continue with the interview questions (see Figure 1). The interviews will be 
carried out individually and audio recorded and will last around 40 minutes.

\subsection{Individual Trial}

This phase comprises a usability test with the BGM and interviews with older people with DM2. The aims of this phase are to (1) identify the errors during the use of the blood glucose meter in a participant from 65 to 75 years of age. (2) Evaluate the effectiveness, efficiency and satisfaction in the use of the glucometer. (3) Determine the compatibility between the user's capacity and the demands of the task. (4) Identify the characteristics of the immediate space where the task is performed, and (5) identify the user's patterns of use within this age group.

\subsubsection{Participants}

The participants will be twenty adults older than 65 years with a diagnosis of DM2 and who receive treatment for this condition. Participants must have a diagnosis by a health professional and have a BGM for glucose monitoring.

\subsubsection{Individual trial}

To achieve the aims in this stage, we have two proposals: perform a Verbal Protocol Analysis (VPA) or fragmenting the task into five sub-tasks, and to decide which is the best option to provide the greatest benefits to carry out this usability test with older adults. For making that decision, a pilot test will be carried out.

The VPA allows the participant to think aloud while doing the task and narrate their actions, desires, needs and problems during use [19]. At the end of this activity, the participant will be interviewed.

In the fragmenting action, the task will allow guiding the task, and at the end of each sub-task, a short interview will be carried out. The task will be fragmented into the five main subtasks, which are obtained from a hierarchical analysis of the previous task, these tasks are: (1) prepare lancing device, (2) configure meter, (3) get the drop, (4) Read results and (5) Remove tests strip and lancet.

\section{Impact Statement}

The main aim of this master's Project is to identify the users' requirements of BGM for older people using Ergonomics methods. Human Factors and Ergonomics systems approaches are critical for improving healthcare quality and patient safety [1] and to provide clinically effective, safe and well-designed medical devices [12]. Ergonomics contribute to the design of all kind of systems with people, as work systems, product or service systems and it focuses on two outcomes: performance and well-being [2]. This approach of user involvement in the design of medical device and systems context is helpful because it allows knowing not only the usability problems but also to generate the user requirements of the device from a systems perspective.

The health sector is extremely complex and is characterised by multiple users, clinical and non-clinical [12] and the importance of clinical efficacy, the safety of the user and the evaluation of user requirements, are between the most important aspects in the design of medical device and skip some factors may compromise the use of medical devices $[6,7,10]$. This work seeks to observe the real-world use of the BGM and identify user requirements, and show the benefits of conducting user-centred research and from a systems context perspective.

This work seeks to continue demonstrating the importance of incorporating an approach from the perspective of Ergonomics to the study of the interaction between final users and medical devices.

\section{Acknowledgments}

We want to thank to the Ergonomics Research Centre and the Master of Ergonomics of the University of Guadalajara.

\section{References}

[1] Carayon, P., Wetterneck, T. B., Rivera-Rodriguez, A. J., Schoofs Hundt, A., Hoonakker, P., Holden, R., and Gurses, A. P. Human Factors Systems Approach to Healthcare Quality and Patient Safety. Applied Ergonomics (2014), 45: 14-25.

[2] Dul, J., Bruder, R., Buckle, P., Carayon, P., Falzon, P., Marras, W. S., Wilsom J. R., and van der Doelen, B. A strategy for human factors/ergonomics: developing the discipline and profession. Ergonomics (2012), 55, 4: 377395

[3] ENSANUT. Encuesta Nacional de Salud y Nutrición de Medio Camino 2016. Retrieved October 20, 2017, from http://promocion.salud.gob.mx/dgps/descargas1/doctos_2016 /ensanut_mc_2016-310oct.pdf

[4] Gao, C., Zhou, L., Liu, Z., Wang, H and Bowers, B. Mobil application for diabetes self-management in China: Do they fit for older adults. International Journal of Medical Informatics (2017), 101, 68-74

[5] Gómez-Dantés, O., Sesma, S., Becerril, V. M., Knaul, M. F., Arreola H. and Frenk, J. The health System of Mexico. Salud Punlica Mex (2011), 53, 2: 220-232

[6] Grocott, P., Weir, H and Bridgelal Ram, M. A model of user engagement in medical device development. Int. J. Health Care Qual. Assur (2007), 20, 6: 484-493.

[7] Howard, S., Lang, A., Sharples, S., Shaw, D. See I Told You I was Taking It!-Attitudes of Adolescents with Asthma towards a Device Monitoring Their Inhaler Use: Implications for Future Design. Applied Ergonomics (2017), 58: 224-237.

[8] INSTITUTO NACIONAL DE SALUD PÚBLICA (INSPI). Diabetes, causa principal de muerte en México. 2017. Retrieved October 10, 2017, from https://www.insp.mx/presencia-insp/3877-presenciainsp.html

[9] Kirk, J. K., and Stegner, J. Self-monitoring of blood glucose: practical aspects. Journal of Diabetes Science and Technology (2010) 4, 2, 435-439.

[10] Lang, A. R., Martin, J. L., Sharples, S., Crowe, J. A. The Effect of Design on the Usability and Real World Effectiveness of Medical Device. Applied Ergonomics, (2013) 44, 799-810.

[11] Lippa, K. D., Klein, H. K., and Shalin, V. L. 2008. Everyday Expertise: Cognitive Demands in Diabetes SelfManagement. Human Factors (2008) 50, 112-120.

[12] Martin, J. L., Norris, B. J., Murphy, E., and Crowe, J. A. Medical device development: the challenge for ergonomics. Applied Ergonomics, (2008) 39: 271-283.

[13] Meléndez-Herrada, E., Sánchez, D. B. J., Ramírez, P. M., Cravioto, A., and Cervantes, E. Diabetes mellitus: aspectos modernos de la problemática Rev Fac Med UNAM (2007) 50, 3: 121-124 
[14] Mexican Diabetes Federation. Llega a mexico Freestyle. 2017. Retrieved December 10, 2017, from http://fmdiabetes.org/llega-a-mexico-freestyle-libre-elrevolucionario-sistema-flash-de-monitoreo-de-glucosa/

[15] Mykityshyn, A. L., Fisk, A. D., and Roger, W. A. Learning to Use a Home Medical Device: Mediating Age-Related Differences with Training. Human Factors (2002) 44: 3, 354364.

[16] Olczurk, D. and Priefer, R. A history of continuous glucose monitors (CGMs) in self-monitoring of diabetes mellitus. Diabetes \& Metabolic Syndrome: Clinical Research \& Reviews (2018) 12, 2: 181-187.
[17] Rogers, W. A., Mykityshyn, A. L., Campbell, R. H., and Fisk, A. D. Analysis of a "Simple" Medical Device. Ergonomics in Design. Ergon (2001) 9, 1: 6-14.

[18] Rojas-Martínez, R., Basto-Abreu, A., Aguilar-Salinas, C. A., Zárate-Rojas, E., Villalpando, S., and Barrientos-Gutiérrez, T. Prevalence of previously diagnosed diabetes mellitus in Mexico. Salud Publica Mex (2018) 60: 224-232. https://doi.org/10.21149/8566

[19] Stanton, N. A., Salmon, P. M., Rafferty, L. A. Walker, G. H., Baber, C., Daniel P. and Jenkins. Human Factors Methods: A practical Guide for Engineering and Design (2nd. Ed.). Ashgate Publishing Limited, Surrey (2013), GU9 7Pt, UK, 39-64. 